\title{
Geopark Bodoquena-Pantanal: análise da inserção do Núcleo de Nioaque, Mato Grosso do Sul
}

\section{Preliminary analysis of the insertion the first center Geopark Bodoquena Pantanal in the city of Nioaque (MS, Brazil)}

Alessandra Trotta, Dores Cristina Grechi, Emerson Machado de Carvalho

\section{RESUMO}

A criação do Geopark Bodoquena-Pantanal se deu em dezembro de 2009, com publicação no Diário Oficial no 7.610. A região sudoeste do Estado é propícia para o desenvolvimento do geoturismo. Sendo assim, o presente trabalho busca discutir e apresentar a relação do Geopark Bodoquena Pantanal com o desenvolvimento do geoturismo, destacando as suas potencialidades e limitações como elementos que podem compor à oferta turística do Núcleo de Nioaque, em Mato Grosso do Sul. Entretanto, a justificativa principal para desenvolver a pesquisa se baseou na criação do Núcleo de Nioaque acerca do Geopark Bodoquena Pantanal, portanto, fazse necessário analisar este novo contexto que se apresenta para o município. Faz-se necessário analisar este novo contexto que se apresenta para o município. Para realizar a análise será utilizada a matriz SWOT (Streghts, Weaknesses, Opportunities e Threads), que significa força, fraqueza, oportunidades e ameaças. Assim, identificou-se quais os pontos fortes a serem explorados, e quais pontos fracos que são necessários trabalhar para eliminar os riscos na gestão do negócio. Esse recurso possibilitou enxergar a situação atual do empreendimento, antecipando o futuro, visualizando as oportunidades e prevenindo as ameaças.

PALAVRAS-CHAVE: Geoparque; Análise; Turismo; Pantanal. 


\section{ABSTRACT}

The creation of the Bodoquena-Pantanal geopark occurred in December 2009, with publication in the Official Gazette No. 7,610. The state's southwestern region is conducive to the development of geotourism. Thus, this paper aims to discuss and present the Geopark Bodoquena Pantanal's relationship with the development of geotourism, highlighting their potentials and limitations as elements that compose the tourist offer of Nioaque Center in Mato Grosso do Sul (Brazil). However, the main justification for developing the research was based on the creation of Nioaque Center about Geopark Bodoquena Pantanal, therefore, it is necessary to review this new context which is presented to the council. To perform the analysis shall include a SWOT matrix (Streghts, Weaknesses, Opportunities and Threads). Thus, we identified the strengths to be explored and what weaknesses we need to work to eliminate the risks in the management of the business. This feature made it possible to see the current situation of the enterprise, anticipating the future, see the opportunities and preventing the threats.

KEYWORDS: Geopark; Analysis; Tourism; Wetland.

\section{Introdução}

O Geoturismo tem se revelado como um segmento do turismo com considerável potencial de crescimento, constituindo-se em uma ferramenta para assegurar a conservação e a sustentabilidade local, por meio da interpretação, conscientização e educação ambiental (DOWLING, 2011; MC KEEVER; ZOUROS, 2005; ZOUROS, 2004). Suas características são exclusivas e peculiares à preservação, ou seja, manutenção da forma inicial e natural do conjunto geológico. Além disso, é possível garantir simultaneamente o desenvolvimento econômico do agrupamento de pessoas que vivem na região contemplada com o geoturismo. Com isso o geoturismo surge como uma atividade importante na conservação e valorização do patrimônio geológico, que faz parte do patrimônio natural.

O Geoturismo está emergindo como um fenômeno mundial, podendo ser definido como um segmento de turismo baseado em visitação e atividades em áreas naturais de cunho geológico (DOWLING, 2011). É uma atividade turística que ressalta as feições geológicas e as apresenta como seu principal atrativo, permitindo o desenvolvimento de um novo olhar, através do entendimento e compreensão da relevância dos aspectos geológicos visitados.

Em 1996 durante o XXX Congresso Internacional de Geologia em Pequim na China, a preocupação dos geólogos Guy Martini e Nicolas Zouros em encontrar uma forma para promoção da gestão sustentável do patrimônio geológico fez com que tivessem a ideia de criar uma iniciativa que permitisse o desenvolvimento sustentável por meio da proteção e promoção do patrimônio geológico com a intenção de desenvolver atividades educativas, científicas e turísticas. A partir disso também faria parte da 
estratégia a conservação desses lugares de interesse geológico (ZOUROS, 2004).

Um importante programa da união europeia de desenvolvimento e cooperação entre zonas rurais (LEADER) possibilitou em 1997 que quatro territórios europeus (Alemanha, Espanha, França e Grécia) desenvolvessem e experimentassem esse então novo conceito, o Geopark, sob a filosofia idealizada pelos geólogos Guy Martini e Nicolas Zouros (MOREIRA, 2011; URQUÍ, 2012).

Em 2000 sob os auspícios da UNESCO, foi criada a Rede Europeia de Geopark (European Geoparks Network - EGN), a primeira do gênero, contando com quatro geoparks, sendo eles: Réserve Géologique de HauteProvence (França), The Petrified Forest of Lesvos (Grécia), Geopark Gerolstein/Vulkaneifel (Alemanha) e Maestrazgo Cultural Park (Espanha) (ZOUROS, 2004; MC KEEVER).

Diante do exposto, o Geopark Bodoquena-Pantanal se destaca como uma importante área para o desenvolvimento, planejamento e gestão do geoturismo no estado do Mato Grosso do Sul. Nesse sentido, o objetivo da presente pesquisa foi fazer uma análise dos aspectos positivos e negativos na gestão do Núcleo do município de Nioaque, que se destaca por ser a área com melhor infraestrutura do Geopark Bodoquena Pantanal.

\section{O conceito de Geopark}

O geopark é uma marca atribuída pela Rede Global de Geoparks sob os auspícios da UNESCO a uma área onde sítios do patrimônio geológico representam parte de um conceito holístico de proteção, educação e desenvolvimento sustentável (MEDEIROS et al., 2015). De acordo com o Instituto do Patrimônio Histórico e Artístico Nacional, as principais características de um geopark são possuir limites bem definidos, promover o desenvolvimento sustentável, cercar sítios geológicos com relevância científica, e excepcionalidade, além de ter uma atribuição ativa no processo de educação ambiental e, através do geoturismo, no desenvolvimento econômico. Não se ignora também os aspectos arqueológicos, ecológicos, históricos e culturais. Ao receber a denominação de geopark há um compromisso explícito em promover ações que visem à proteção do patrimônio geológico e o desenvolvimento sustentável (IPHAN/MS, 2010).

Em 13 de fevereiro de 2004 foi criada a Global Geoparks Network (GGN) em reunião realizada na sede da UNESCO, em Paris, da qual participaram os membros do Conselho Científico do Programa Internacional de Geociências - IGCP, representantes da União Geográfica Internacional IGU e da União Internacional das Ciências Geológicas - IUGS, além de especialistas internacionais sobre a conservação e promoção do patrimônio geológico (URQUí, 2012). A GGN é uma rede internacional não governamental, voluntária e sem fins lucrativos que fornece uma plataforma de cooperação entre os geoparks e reúne órgãos governamentais, organizações não governamentais, cientistas e comunidades de todos os países ao redor do mundo em uma única parceria global, operando de acordo com os regulamentos da UNESCO (EDER; PATZAK, 2004). 
Durante a I Conferência Internacional de Geoparks realizada na China, em junho de 2004 a Rede Global de Geoparks era composta por 25 geoparks (17 europeus e 8 chineses). Atualmente a rede já possui 111 geoparks em 32 países de diversas partes do mundo.

Um geopark, no entanto, deve evidenciar na localidade sua identidade histórica e geológica, o modo de ser de suas populações locais, sua cultura e tradições. Segundo Boggiani (2010, p. 02):

\begin{abstract}
$\mathrm{Na}$ criação de um geopark, leva-se em consideração que cada parte do planeta tem seu próprio espírito do lugar, muitas vezes relacionado aos aspectos geológicos, como presença de cavernas, atividades de garimpo, relevo montanhoso, entre outros que se reflete no modo de ser e na cultura das populações locais e o entendimento é que o geoturismo, como principal atividade a ser desenvolvida em um geopark, venha a ser a chave dessa interpretação.
\end{abstract}

No Brasil, existem várias propostas para implantação de geoparks. Estes são viabilizados através dos embasamentos propostos pelo "Projeto Geoparks", criado em 2006 pelo Serviço Geológico do Brasil - CPRM. O projeto tem como premissa básica a identificação, levantamento, descrição, inventário, diagnóstico e ampla divulgação de áreas com potencial para futuros geoparks em território nacional (CPRM - 2011). Segundo Schobbenhaus (2003), o país apresenta várias áreas potenciais para implantação de Geoparks, fato possível devido sua vasta extensão continental. No mesmo caminho, Medeiros et al. (2015) argumenta que na concepção de um geopark é necessário também se pensar no desenvolvimento do geoturismo, apontado como uma atividade relevante para conservação dos aspectos geológicos e que, no entanto, precisa ser reconhecido, difundido e valorizado.

\title{
Desafios do Geoturismo
}

Um segmento bastante recente e que vem despertando interesse em vários locais do mundo é o "geoturismo" (MANOSSO, 2007). Apesar do recente interesse, o geoturismo e o turismo mineral já existem há vários anos em países da Europa e Estados Unidos, definindo um produto turístico de grande valor e sem limitação de durabilidade como os produtos artificiais (PERINOTTO, 2009). Trata-se de um novo segmento do turismo de natureza e que surge com a intenção de divulgar o patrimônio geológico, bem como possibilitar sua conservação (NASCIMENTO et al., 2007).

Considerando-se a evolução da atividade de turismo nas últimas décadas, o termo "geoturismo" pode ser vinculado ao conceito de desenvolvimento sustentável do turismo (PERINOTTO, 2009). Dessa forma, atribui-se ao geoturismo as potencialidades de se tornar um empreendimento turístico economicamente viável, e que favoreça o desenvolvimento social justo e a preservação e conservação dos recursos 
naturais locais. No entanto, os desafios desse segmento turístico vão além dos seus aspectos voltados à sustentabilidade.

O turismo atualmente apresenta novos desafios que vão além do turismo de destino. Ele deve proporcionar experiências e experimentações. Dessa forma, o geoturismo pode oferecer uma oportunidade para uma aproximação com o público, além de ser um novo produto de turismo direcionado a pessoas motivadas por conhecimento intelectual e por atividades que envolva aprendizado, exploração, descoberta e imaginação (NASCIMENTO et al., 2007). Essa atividade permite um novo olhar à visitação turística, de forma a permitir o entendimento dos locais visitados, resultando na compreensão e importância daqueles aspectos geológicos, promovendo sua conservação (MEDEIROS et al., 2015).

Além dos aspectos mencionados, o geoturismo é uma forma sinérgica de turismo, onde os elementos da paisagem e as formas de relevo, juntos, criam uma experiência turística que é mais rica do que a soma das partes (MEDEIROS et al., 2015). Ele deve estar conectado e integrado a outros segmentos turísticos, como o ecoturismo, turismo de aventura, turismo cultural, entre outros. Dessa forma, é perceptível o grande desafio a superar no planejamento e gestão do turismo no Geopark Bodoquena Pantanal.

\section{Geopark Bodoquena-Pantanal}

Entre inúmeras possibilidades de turismo no Brasil, a região da Serra da Bodoquena e Pantanal, localizada no Mato Grosso do Sul, desperta grande interesse nos turistas. Através do Decreto Estadual no 12.897, de 22 de dezembro de 2009 (BRASIL, 2009), foi criado o Geopark Estadual Bodoquena-Pantanal. Sua área é $20.000 \mathrm{~km}^{2}$ e delimita-se por uma poligonal irregular disposta num sentido aproximado sudeste-noroeste, abrangendo a serra da Bodoquena e entorno imediato, bem como áreas do Pantanal do Jacadigo-Nabileque e da região de Corumbá (Figura 1). Os municípios abrangidos possuem uma população de cerca de 265.000 habitantes. O entorno do Geopark Estadual Bodoquena-Pantanal possui $39.000 \mathrm{~km}^{2}$. O território abrange 13 municípios: Anastácio, Aquidauana, Bela Vista, Bodoquena, Bonito, Caracol, Corumbá, Guia Lopes da Laguna, Jardim, Ladário, Miranda, Nioaque e Porto Murtinho, apresentando uma região vasta cuja história geológica, que remonta há cerca de 2 mil milhões de anos, é um elemento unificador do território do geopark.

O Geopark Bodoquena-Pantanal apresenta um embasamento geológico do Paleoproterozoico num registo que chega até à atualidade. De acordo com o Decreto Estadual n. 012.897 estão inventariados 54 geossítios de interesse geomorfológico, tectônico, estratigráfico, sedimentológico, paleontológico, espeleológico, mineralógico e hidrogeológico que revelam a importante Geodiversidade do território (SOARES et al., 2014).

No Geopark Bodoquena Pantanal estão inclusos vários geossítios, entre grutas, pedreiras, baías, minas, cachoeiras, nascentes e monumentos, além da presença de fósseis dos primeiros habitantes da Terra. Essa riqueza disponível desperta o desenvolvimento do geoturismo. 
O cenário do Geopark Bodoquena Pantanal pode ser concebido como um espaço concreto e visível do espaço geográfico, onde é realizável a identificação e caracterização dos elementos mais interessantes do ponto de vista ambiental, cultural, etc. Nesta situação, alguns dos elementos concedem um subsídio importante para as sugestões de roteiros que possibilitam ao turista a leitura das particularidades mais acentuadas do lugar.

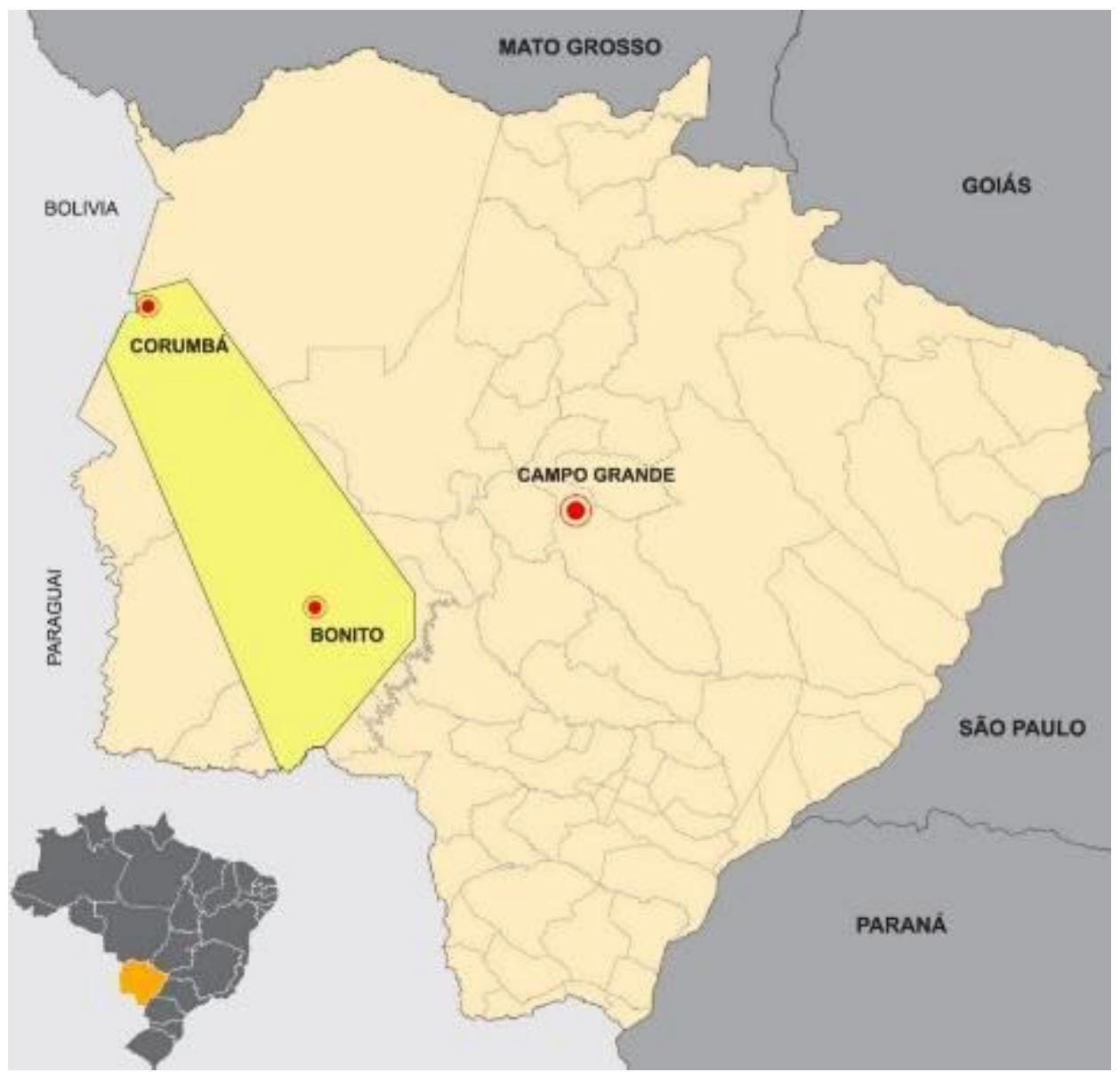

Figura 1: Demarcação da área do Geopark Bodoquena-Pantanal. Fonte: IPHAN/MS (2010). Figure 1: Demarcation of the Geopark Bodoquena Pantanal area. Source: IPHAN/MS (2010).

Dentro da área do Geopark Estadual Bodoquena-Pantanal existem diversas potencialidades que podem ser exploradas turisticamente e cientificamente como, por exemplo, os sítios arqueológicos, paleontológicos e geológicos. De acordo com o cadastro nacional de sítios arqueológicos do IPHAN - Instituto do Patrimônio Histórico e Artístico Nacional, o Estado de Mato Grosso do Sul possui cerca de 650 sítios arqueológicos cadastrados até o momento. Estes sítios encontram-se especialmente em regiões fluviais dos rios Paraguai e Paraná. Apesar de haver na região um interesse paisagístico e turístico, o contexto da Serra da Bodoquena e seus ambientes fluviais de entorno nos municípios circundantes, seu conteúdo arqueológico é pouco conhecido. Neste sentido, trabalhos voltados à arqueologia nas regiões do entorno da Serra da Bodoquena, contribuem para interpretação científica acerca do povoamento pretérito da região através do resgate dos vestígios arqueológicos e salvaguarda do patrimônio arqueológico além de 
viabilizar o desenvolvimento de atividades como a educação patrimonial, visando à ampliação da percepção da comunidade local acerca do patrimônio arqueológico e da necessária definição de práticas de preservação desses testemunhos culturais e de seus ambientes associados.

Dessa forma, a presente pesquisa pretende explorar as potencialidades do desenvolvimento turístico no Geopark Bodoquena Pantanal, principalmente dos geossítios da cidade de Nioaque - MS, ressaltando assim seus aspectos positivos e negativos, bem como as ameaças e oportunidades do Núcleo.

\section{Material e Métodos}

A presente pesquisa foi desenvolvida na forma de um estudo qualitativo, do tipo exploratório-descritivo, uma vez que não se vale de instrumentos estatísticos no processo de análise do problema. Os meios utilizados para o levantamento dos dados foram: 1) observação in locu do Núcleo de Nioaque; 2) conversa informal com gestores do Núcleo e Geopark; 3) pesquisa a materiais informativos e de divulgação do Núcleo e Geopark (impressos e online) e; 4) pesquisa a artigos científicos sobre o Núcleo e sobre o tema.

Para compilação dos dados foi utilizado o método SWOT - Strengths, Weaknesses, Opportunities, Threats - como ferramenta de análise, com base em informações obtidas no levantamento. O SWOT é uma ferramenta que permite a análise dos pontos fortes, fracos, oportunidades e ameaças de um atrativo ou empreendimento sob a perspectiva, nesse caso, do pesquisador e dos gestores.

Com base nas informações obtidas, foi construído um quadro com os aspectos internos (pontos fortes e fracos) e externos (ameaças e oportunidades), a partir do qual foi realizada uma análise dos fatores apontados, suas sinergias e antagonismos, e propostas ações de manejo que podem ser incorporadas no processo de planejamento e gestão do geossítio. Segundo Ghemawat (2000), o objetivo atual de uma análise SWOT - streghts, Weaknesses, opportunities and threads é identificar as forças, fraquezas, oportunidades e ameaças de um determinado projeto, empresa ou situação, e definir estratégias para manter os pontos fortes, reduzir a intensidade dos fracos, aproveitando as oportunidades e protegendo-se dos riscos que poderão impactar negativamente o projeto.

Como ferramenta de apoio foi utilizada programa Luz Planilhas Empresarias. O programa permitiu cruzar os dados (fatores internos e externos), fazer uma representação gráfica dos resultados e propor recomendações para análise.

\section{Resultados e Discussão}

A área estudada é o munícipio de Nioaque - MS, onde foram encontradas pegadas de dinossauros impressas em arenitos eólicos jurássicos (Figura 2) da Formação Botucatu, unidade hidrogeológica mais importante do Aquífero Guarani e associada à Bacia Serra Geral 
(IPHAN/MS, 2010). Conforme o Decreto Estadual N.ํ 12.897 de 22.12.09, que dispõe sobre a criação do Geopark Bodoquena-Pantanal, existe em Nioaque um só geossítio inventariado, Icnofósseis/Formação Botucatu, localizado na fazenda Minuano, margem direita do rio Nioaque.

Com o intuito de facilitar o processo de gestão do Geopark Bodoquena - Pantanal foi proposto um conjunto de áreas núcleo, que são conjuntos de geossítios articulados pela sua identidade geológica e cultural. O conceito de núcleo regional do Geopark Bodoquena-Pantanal surge para dar resposta à dificuldade de gestão, pelo fato de ser um geopark com área bastante extensa (SOARES et al., 2014).

A riqueza geológica do munícipio de Nioaque permitiu que no Geopark Bodoquena-Pantanal fosse criado o primeiro núcleo do Geopark estabelecendo um protocolo de cooperação e um Plano de Trabalho. Segundo Soares et al., (2014) os Núcleos são estabelecidos em parceria com Prefeituras, ONGs, empresários privados, entidades que assegurem estabilidade ao projeto e garantam o espaço, equipamentos e os recursos humanos. De acordo com os autores, o objetivo destes polos é que sejam centros dinamizadores das Geociências e promovam a divulgação da cultura científica atuando também como Centro de Visitantes e ou de Atendimento a Turistas.

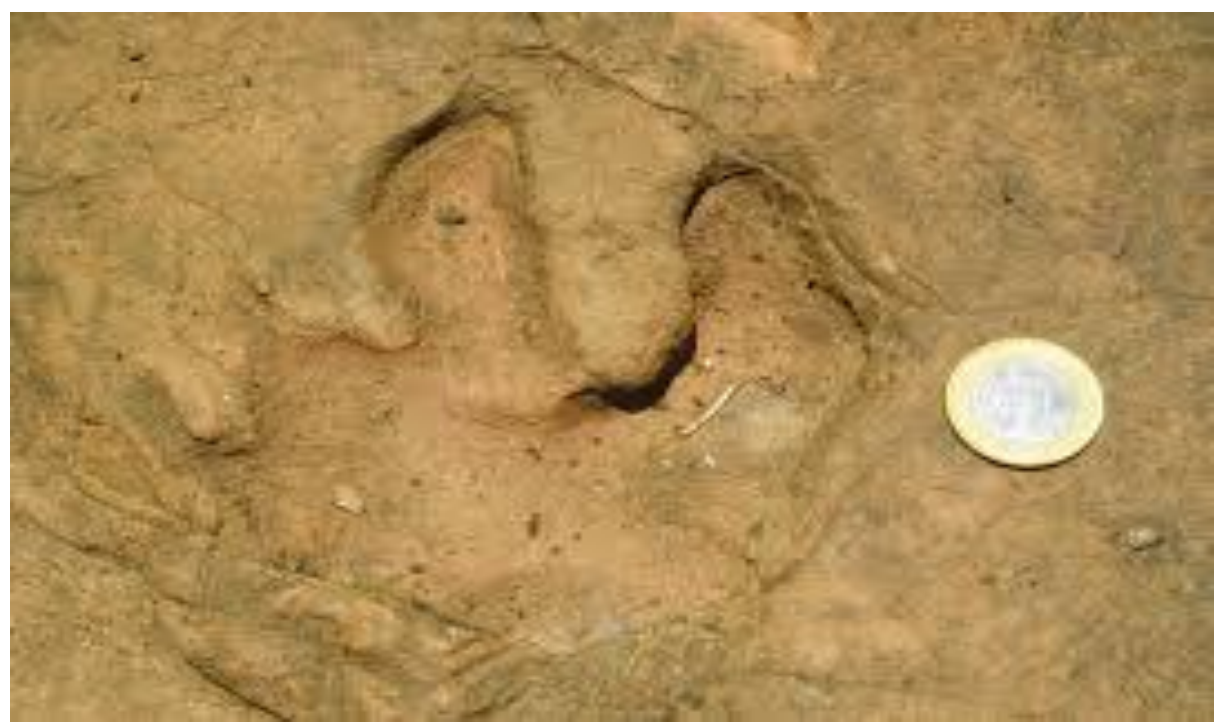

Figura 2: Geossítio, Pegadas de Dinossauros de Nioaque. Icnofósseis/Formação Botucatu. Fonte: IPHAN/MS (2010).

Figure 2: Geosite, Nioaque footprints of dinosaurs. Ichnofossils / Botucatu Formation. Source: IPHAN/MS (2010).

Através de uma visita realizada ao município de Nioaque e ao respectivo núcleo foram levantados vários aspectos negativos (ameaças, e pontos fracos) e aspectos positivos (oportunidades e pontos fortes) que compuseram uma matriz SWOT (Quadro 1). 
Quadro 1: Matriz SWOT da situação do Núcleo Regional Geopark Bodoquena-Pantanal de Nioaque. Entre parêntese valores atribuídos pelos pesquisadores a cada item, onde: 0 totalmente sem importância; 2,5 - pouco importante; 5,0 - importante; 7,5 - muito importante; 10 - totalmente importante.

Table 1: SWOT matrix of the situation of the Regional Center Geopark Bodoquena -

Pantanal Nioaque. In brackets values attributed by the researchers to each item, where zero - full - mind unimportant; 2.5 - unimportant; 5.0 - important; 7.5 - very important; 10 completely important.

\begin{tabular}{|c|c|c|}
\hline & Aspectos positivos & Aspectos negativos \\
\hline & $\begin{array}{l}\text { Pontos fortes } \\
\text { (10) Estrutura física do núcleo sendo instalada e } \\
\text { um bom potencial de uso. } \\
\text { (10) Apoio do governo municipal a inserção do } \\
\text { núcleo no município. } \\
\text { (10) Boa localização do Núcleo Nioaque. } \\
(7,5) \text { Existência do Conselho Gestor do Geopark } \\
\text { no município de Nioaque. } \\
(7,5) \text { Empenho dos envolvidos no projeto para o } \\
\text { término do núcleo } \\
(5,0) \text { Potencial para implantação de atividades } \\
\text { recreativas. } \\
(5,0) \text { Formação dos professores e alunos da } \\
\text { rede municipal em parceria com o } \\
\text { Geopark. }\end{array}$ & $\begin{array}{l}\text { Pontos fracos } \\
\text { (10) Falta de recursos para apoiar o } \\
\text { andamento da instalação do } \\
\text { núcleo. } \\
(7,5) \text { Equipe do Geopark pequena. } \\
(7,5) \text { Dificuldade para acessar as } \\
\text { pegadas de dinossauros. } \\
(7,5) \text { Inexistência de um sistema de } \\
\text { trilhas abertas para a visitação } \\
\text { pública. }\end{array}$ \\
\hline 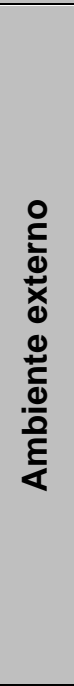 & $\begin{array}{l}\text { Oportunidades } \\
\text { (10) Ser o primeiro núcleo do Geopark } \\
\text { Bodoquena Pantanal a ser implantado } \\
\text { (10) Apropriação da comunidade. Pensamentos } \\
\text { empreendedores acerca do tema. } \\
(7,5) \text { Um novo segmento turístico para o estado. } \\
(7,5) \text { Turismo Científico e Geoturismo. Local } \\
\text { atrativo para pesquisa. . } \\
(7,5) \text { Boas condições de acesso à cidade de } \\
\text { Nioaque. } \\
(5,0) \text { Turismo com escolas locais e regionais. } \\
(5,0) \text { Várias universidades e institutos de } \\
\text { pesquisa localizados em municípios } \\
\text { relativamente próximos a cidade de } \\
\text { Nioaque. } \\
\text { (10) Conflito de identidade turística para o } \\
\text { município: Histórico cultural e Geoturismo. }\end{array}$ & $\begin{array}{l}\text { Ameaças } \\
\text { (10) Falta de conhecimento do } \\
\text { cidadão sul-mato-grossense } \\
\text { acerca do Geopark. } \\
(7,5) \text { O caminho até as pegadas se } \\
\text { encontra em propriedade } \\
\text { particular. } \\
(7,5) \text { Possível descontinuidade de } \\
\text { ações dada por mudanças de } \\
\text { governo estadual e municipal. } \\
(2,5) \text { Conflito de identidade turística } \\
\text { para o município: Histórico } \\
\text { cultural e Geoturismo. }\end{array}$ \\
\hline
\end{tabular}

Com a análise SWOT desenvolvida pôde-se identificar que a inserção do Núcleo, apesar de estar encaminhada, demanda, ainda, um processo de planejamento e gestão que podem ser reunidos em três diferentes temas: infraestrutura turística, produtos e serviços ofertados, geoturismo urbano. A seguir a descrição de cada um dos temas:

\section{Infraestrutura Turística}

Apesar da existência do núcleo no município de Nioaque, o local de acesso a trilha ainda não apresenta um estudo de capacidade de carga e se encontra em propriedade particular o que dificulta o livre acesso. 
Outro aspecto relevante é a infraestrutura das estradas que levam à cidade. Os três acessos diferentes para o município de Nioaque se encontraram em bom estado de conservação e sinalização no dia em que foi feito a visita in loco. No local há um monumento temático (Figura 3).

Figura 3: Monumento na entrada da cidade de Nioaque pela BR-060.

Figure 3: Monument at the entrance of the city of Nioaque the BR- 060.

\section{Produtos e Serviços ofertados}

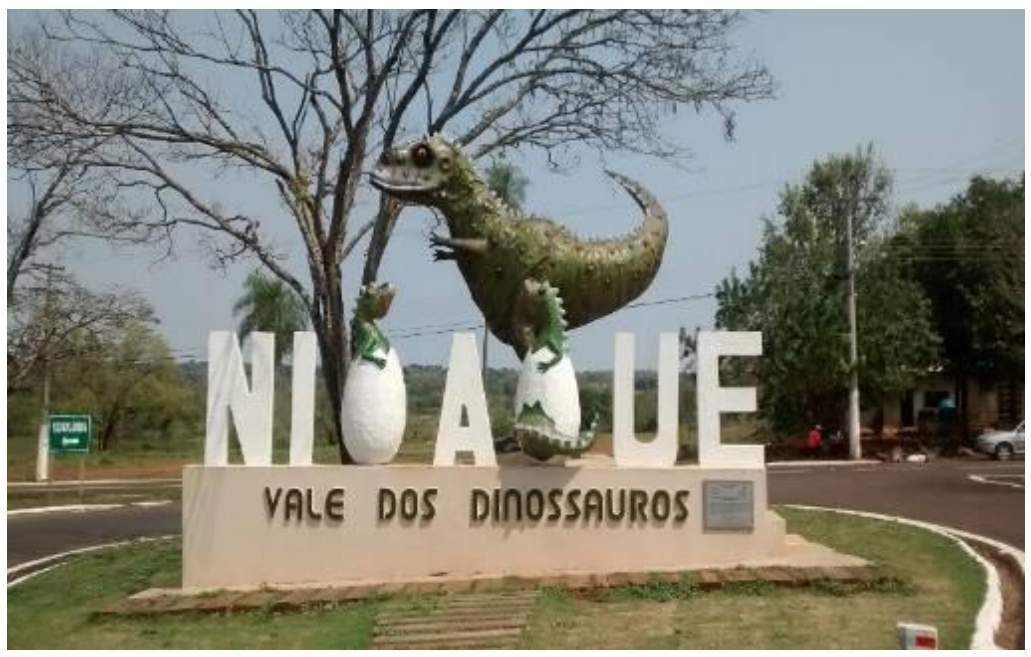

Uma importante similaridade do geoturismo com o ecoturismo é a capacidade de dinamizar economias estagnadas nas áreas do entorno dos atrativos, bem como propiciar a conservação das áreas por iniciativa própria das comunidades locais através da geração de renda a partir dos atrativos turísticos geológicos (LASCURÁIN, 2011).

Alguns empreendedores já estão utilizando dessa identidade agregada ao município, um exemplo é a criação de alimentos temáticos. Além do planejamento de para confecção de souvenires temáticos, como camisetas, além do interesse de um empreendedor local na criação de um hotel temático.

O geossítio está localizado a 2,7 quilômetros a jusante da ponte sobre o rio Nioaque, distribuído as margens deste mesmo rio, na fazenda Minuano. Atualmente a maior parte da população já se encontra em áreas urbanas, portanto a ideia é disponibilizar o conhecimento geológico no meio urbano, incluindo a população nas discussões que acercam patrimônio geológico e geoconservação. Liccardo, Neto e Piekarz (2012, p.141.) afirmam que "Desenvolver o geoturismo dentro de núcleos urbanos pode contribuir para uma difusão mais rápida do tema "patrimônio geológico" entre a população e gradativamente causar um reflexo positivo na educação formal”.

Com a instalação do primeiro Núcleo e o Geomuseu do Geopark Bodoquena Pantanal essa definição de Geoturismo Urbano se adequa aos trabalhos que lá vem sendo desenvolvido, que são palestras e atividades práticas direcionadas aos alunos da rede municipal-estadual, que visam propagação das geociências e conscientização sobre as pegadas, aprendendo o que são fósseis através de réplicas. Outra atividade realizada 
é o "Cine Geopark", vem sendo desenvolvido toda quarta-feira no núcleo e consiste em uma atividade de lazer educativa, aberta a comunidade. No "Cine Geopark" são exibidos filmes e documentários com a temática de dinossauros (Figura 4).

Figura 4: Conscientização e familiarização sobre as pegadas de dinossauro.

Figure 4: Awareness and familiarization on the dinosaur footprints.

\section{Cruzamento de dados SWOT}

O cruzamento de dados é uma importante etapa na análise SWOT,

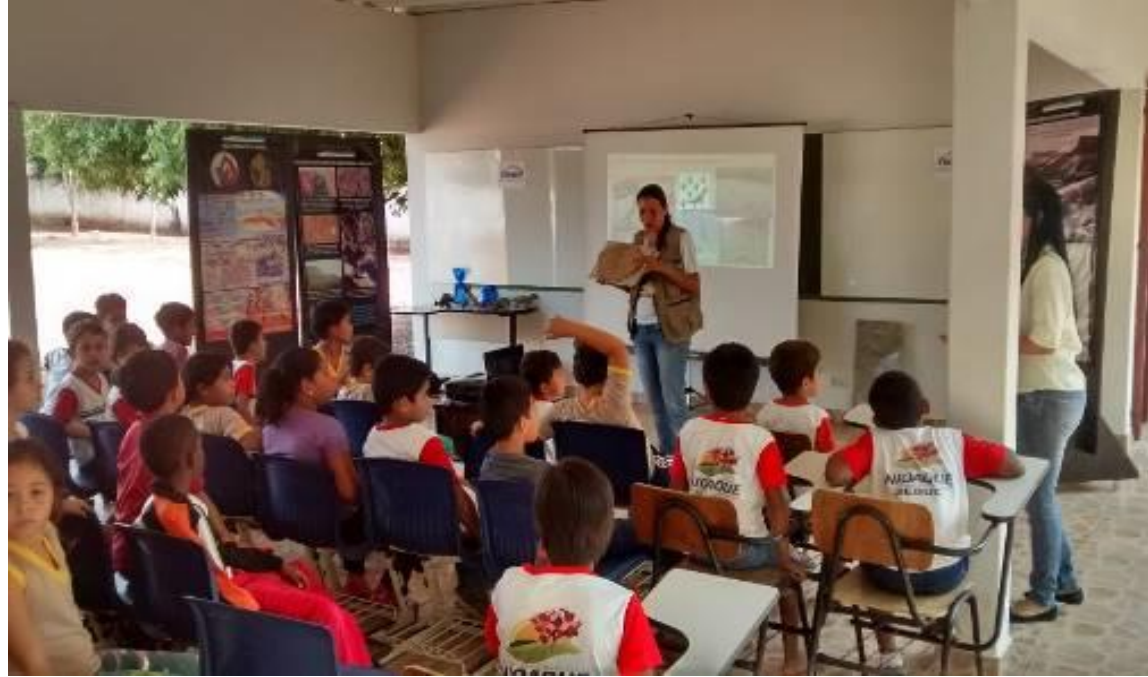

pois é a oportunidade de traçar planos para potencializar o que tem de melhor e se preparar para possíveis problemas.

$\mathrm{Na}$ Tabela 1 foram cruzadas as quatro principais forças (as mais bem pontuadas em "fatores internos") com suas oportunidades. As ações propostas, no entanto, são resultado de um cruzamento entre as forças e oportunidades, em que foi possível desenvolver estratégias que impulsionassem as forças com a ajuda das oportunidades. Essas estratégias são bem focadas no desenvolvimento turístico e econômico da cidade. Além disso, tem-se estabelecido como estratégia a aceitação, participação e integração da comunidade local com o desenvolvimento turístico. De acordo com as definições para a criação de um geopark, além de se pautar o desenvolvimento no conceito de sustentabilidade por meio do geoturismo, deve-se, ainda, promover o respeito ao meio ambiente e a promoção social e econômica da região com desenvolvimento e atração de novos negócios. 
Tabela 1: Resultado do cruzamento de dados Forças versus Oportunidades.

Table 1: Data crossing Result Forces versus Opportunities.

\begin{tabular}{|c|c|c|}
\hline Principais forças & Suas oportunidades & $\begin{array}{l}\text { Como a oportunidade pode } \\
\text { potencializar a força? }\end{array}$ \\
\hline $\begin{array}{l}\text { Estrutura física do Núcleo } \\
\text { sendo instalada e um bom } \\
\text { potencial de uso. }\end{array}$ & $\begin{array}{l}\text { Apropriação da comunidade, } \\
\text { pensamentos empreendedores com } \\
\text { relação do tema. }\end{array}$ & $\begin{array}{l}\text { Aceitação da comunidade e o } \\
\text { crescimento do seguimento em } \\
\text { conjunto com a população. }\end{array}$ \\
\hline $\begin{array}{l}\text { Apoio do governo } \\
\text { municipal para inserção } \\
\text { do Núcleo no município. }\end{array}$ & $\begin{array}{l}\text { Várias universidades e institutos de } \\
\text { pesquisa localizados em municípios } \\
\text { relativamente próximos a cidade de } \\
\text { Nioaque. }\end{array}$ & $\begin{array}{l}\text { Potencial de investimento e } \\
\text { visibilidade para pesquisas. }\end{array}$ \\
\hline $\begin{array}{l}\text { Boa localização do } \\
\text { Núcleo Nioaque. }\end{array}$ & $\begin{array}{l}\text { Boas condições de acesso à cidade } \\
\text { de Nioaque. }\end{array}$ & Aumentar as visitações \\
\hline $\begin{array}{l}\text { Existência do Conselho } \\
\text { Gestor do Geopark no } \\
\text { município de Nioaque. }\end{array}$ & $\begin{array}{l}\text { Um novo segmento turístico para o } \\
\text { munícipio. }\end{array}$ & $\begin{array}{l}\text { Crescimento } \\
\text { empreendimentos turísticos }\end{array}$ \\
\hline
\end{tabular}

Na Tabela 2, responsável pelo cruzamento de Forças e Ameaças, foi possível ver o potencial ofensivo e desenvolver a melhor estratégia para impulsionar as forças e minimizar as ameaças. As estratégias apresentadas estão alicerçadas no planejamento dos atrativos de forma a minimizar os danos ambientais e o fortalecimento das políticas públicas, parcerias e divulgação do atrativo.

Entre as ações propostas algumas já se encontram em andamento. É o caso da criação de um ambiente que possibilite conhecer sobre as pegadas sem precisar da visita in loco. Através do núcleo essa proposta será executada, pois nele será possível conhecer as espécies que ali existiram e réplicas das pegadas que se encontram no município.

Parcerias também são realizadas conforme levantado através de conversa informal com os responsáveis pelo núcleo, e a divulgação e conscientização sobre o tema para a população do estado, que apesar de esporádica, é realizada com participação do Geopark Bodoquena Pantanal em eventos do estado e também com o Núcleo móvel que leva informação a respeito do geopark e também o núcleo do Geopark no município de Nioaque-MS. De acordo com Nascimento et al. (2007), o geoturismo requer um planejamento prévio e adequado para se consolidar e se desenvolver garantindo o sucesso da atividade. Além disso, deve mitigar os impactos ambientais e dos problemas socioeconômicos, bem como a conservação do patrimônio natural. 
Tabela 2: Resultado do cruzamento de dados Forças versus Ameaças.

Table 2: Data crossing Result Forces versus Threats.

\section{Principais forças}

Suas Ameaças
Como pode minimizar sua Ameaça com sua força?
Estrutura física do Núcleo As pegadas estarem localizadas sendo instalada e um no leito do rio, podendo ser bom potencial de uso. danificadas e extintas com $O$ tempo.
Criação de um ambiente que possibilite conhecer sobre as pegadas sem precisar fazer a visita in loco.

Apoio do governo Possível descontinuidade de Leis que favorecem a continuidade municipal para inserção ações dada por mudanças de das ações do Geopark no do Núcleo no Município. governo estadual e municipal. município.

Boa localização do $O$ caminho até as pegadas se Parceria Núcleo Nioaque. encontra em propriedade particular.

Existência do Conselho Falta de conhecimento do cidadão Gestor do Geopark no sul matogrossense sobre município de Nioaque.
Geopark.
Divulgação e conscientização sobre o tema para a população do estado.

$\mathrm{Na}$ Tabela 3 é possível visualizar o cruzamento entre Fraquezas e Oportunidades. Dessa forma, foi possível ver o potencial ofensivo e desenvolver a melhor estratégia para impulsionar as oportunidades e minimizar as fraquezas. A falta de recursos para apoiar o andamento da instalação do núcleo tem como proposta recorrer a ajuda do cidadão, pois houve uma apropriação da comunidade, pensamentos empreendedores acerca do tema. Sobre a equipe do Geopark ser pequena, valoriza-se a oportunidade de possuir várias universidades e institutos de relativamente próximos a cidade. E mais uma vez a promoção da participação da comunidade, a busca por parcerias e a importância em se investir numa nova modalidade turística ganha força no planejamento e gestão do geopark.

Tabela 3: Resultado do cruzamento de dados Fraquezas versus Oportunidades.

Table 3: Data crossing Result versus Weaknesses Opportunities.

Principais fraquezas

Suas Oportunidades

\section{Como diminuir sua}

Fraqueza com

Oportunidade?

Falta de recursos para Apropriação da comunidade, Recorrer à ajuda do cidadão. apoiar 0 andamento da instalação do núcleo.

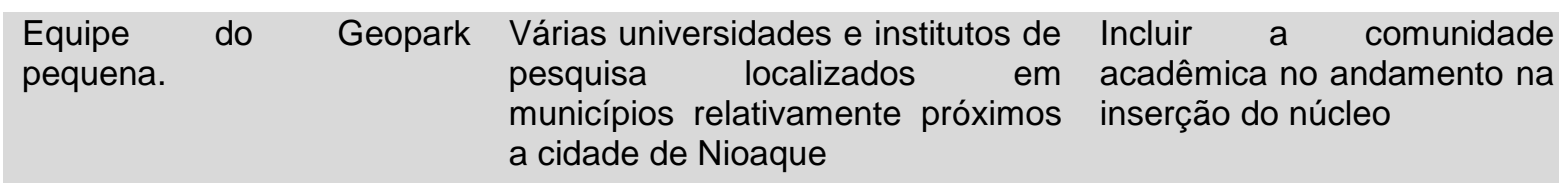

Dificuldade para acessar as Boas condições de acesso à Parcerias pegadas de dinossauros.
Inexistência de um sistema Um novo segmento turístico para o Geoturismo Urbano de trilhas abertas para a munícipio.

visitação pública. 
$\mathrm{Na}$ Tabela 4, responsável pelo cruzamento entre Fraquezas e Ameaças, foi possível visualizar linhas de ações planejadas a partir da análise das ameaças. É o caso da falta de conhecimento da população do núcleo de Nioaque que deverá ser suprida com divulgação para a população sul-mato-grossense. Envolver a comunidade no planejamento foi outra importante linha de ação para minimizar a questão relacionada à limitação da equipe do geopark e, consequentemente, à ameaça da possível descontinuidade das ações relacionadas às mudanças de governo.

Tabela 4: Resultado do cruzamento de dados Fraquezas versus Ameaças.

Table 4: Cross-checking the outcome Weaknesses versus threats.

\begin{tabular}{|c|c|c|}
\hline Principais fraquezas & Suas Ameaças & $\begin{array}{c}\text { Qual será a estratégia } \\
\text { para diminuir sua perda? }\end{array}$ \\
\hline $\begin{array}{l}\text { Falta de recursos para } \\
\text { apoiar o andamento da } \\
\text { instalação do núcleo. }\end{array}$ & $\begin{array}{l}\text { Falta de conhecimento do cidadão } \\
\text { sulmatogrossense acerca do Geopark. }\end{array}$ & Divulgação. \\
\hline $\begin{array}{l}\text { Equipe do Geopark } \\
\text { pequena. }\end{array}$ & $\begin{array}{l}\text { Possível descontinuidade de ações } \\
\text { dada por mudanças de governo } \\
\text { estadual e municipal. }\end{array}$ & $\begin{array}{l}\text { Envolver a comunidade por } \\
\text { completo. }\end{array}$ \\
\hline $\begin{array}{l}\text { Dificuldade para acessar } \\
\text { as pegadas de } \\
\text { dinossauros. }\end{array}$ & $\begin{array}{l}\text { As pegadas estarem localizadas no leito } \\
\text { do rio, podendo ser danificadas e } \\
\text { extintas com o tempo. }\end{array}$ & Réplicas das pegadas. \\
\hline $\begin{array}{l}\text { Inexistência de um } \\
\text { sistema de trilhas abertas } \\
\text { para a visitação pública. }\end{array}$ & $\begin{array}{l}\text { O caminho até as pegadas se encontra } \\
\text { em propriedade particular. }\end{array}$ & Parceria. \\
\hline
\end{tabular}

Outro resultado interessante, gerado pelo programa utilizado, referese ao índice de favorabilidade. O índice é gerado após toda a análise SWOT e o cruzamento de dados junto às pontuações obtidas. O resultado foi $20 \%$, exatamente centralizado, o que significa um cenário equilibrado no que se refere à implantação do Núcleo no município de Nioaque-MS. No entanto, vale investir mais tempo, com uma análise mais detalhada para que se descubra o que se faz necessário focar quanto aos fatores internos ou externos e progredir em resultados mais específicos.

Em suma, a pontuação final da análise SWOT (Figura 5) gerou algumas recomendações pelo programa, como:

-As forças estão mais altas que suas fraquezas, indicando um bom andamento do empreendimento turístico;

- Têm-se mais oportunidades do que ameaças, o que indica um futuro promissor, é necessário identificar e alinhar quais forças vão aperfeiçoar as chances das oportunidades acontecerem de fato;

- Mesmo as ameaças estando mais baixas que as oportunidades, ainda assim, valem a pena analisar as ameaças mais relevantes e criar planos de ações para elas. 


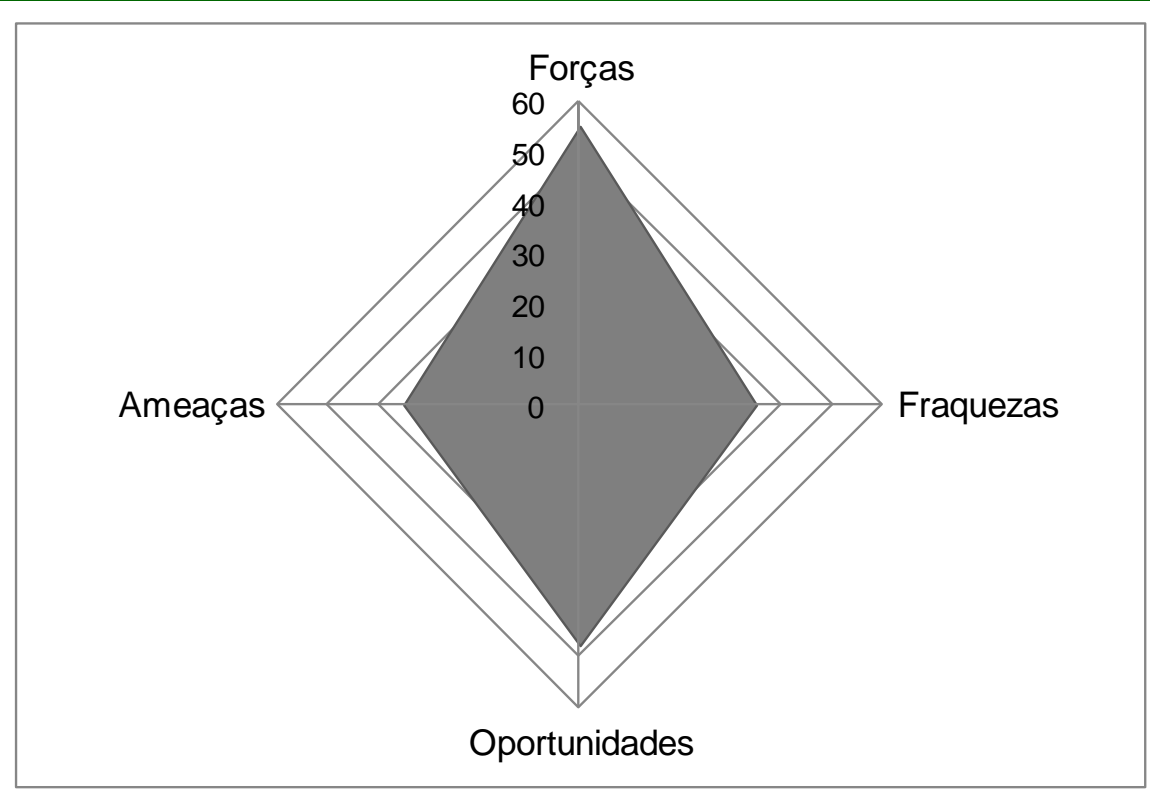

Figura 5: Resultado final da pontuação da matriz SWOT. Figure 3: Result of the SWOT matrix score.

\section{Considerações Finais}

Por meio do conteúdo apresentado, pode-se perceber a relevância da temática, e a sua importância para o desenvolvimento regional, não somente na região de Nioaque, mas para todo o estado de Mato Grosso do Sul.

A inserção de um Geopark em uma localidade oportuniza alternativas de planejamento e gestão compartilhada entre poder público, empresários, ONGs, artesãos, universidades, escolas e comunidade local. O Geopark Bodoquena Pantanal se encontra em um processo de inserção e sensibilização da comunidade local. Um exemplo disso é a instalação de núcleos nas localidades que se encontram os geossítios, como é o caso do município de Nioaque-MS objeto de estudo do presente trabalho.

A população local através dos projetos realizados no Núcleo vem se inserindo e se tornando parte dessa grande transformação do município. $O$ tema Geopark já está disseminado na cidade, e esse novo tema entra como uma oportunidade de crescimento e geração de renda local.

O geoturismo ainda não representa uma realidade para o município de Nioaque, pela recente inserção do Geopark e seu respectivo Núcleo. Trata-se de uma novidade para a comunidade, apesar das pegadas serem conhecidas pelos moradores há algum tempo. No entanto a sua importância geológica só veio tomar sentido após o interesse por parte de pesquisadores e os desdobramentos dos projetos envolvendo a comunidade. Portanto, incluir a população e a comunidade acadêmica do entorno, e até mesmo do estado trará maior visibilidade por parte da população, e assim novas estratégias turísticas poderão ser pensadas em conjunto com a comunidade.

Geoturismo urbano é a definição mais adequada no que vem sendo desenvolvido no primeiro Núcleo do Geopark Bodoquena Pantanal no município de Nioaque. $O$ desenvolvimento do geoturismo dentro desse 
núcleo urbano vem contribuindo para uma difusão mais rápida acerca de patrimônio geológico, e é uma oportunidade para aproximação com o público, além de ser um segmento direcionado a pessoas motivadas por conhecimento e atividades que envolvam aprendizado.

Os esforços na sensibilização da comunidade e a sua participação no planejamento do núcleo vem difundindo um sentimento de pertencimento e entendimento da importância da existência daqueles Icnofósseis/ Formação Botucatu para o município. Para a UNESCO, um geopark precisa ter uma área que tenha significativas exposições geológicas, paleontológicas ou geomorfológicas e que haja uma população no seu interior, a qual deverá ser beneficiada com a sua criação.

Portanto, através da pesquisa realizada observou-se que a inserção do primeiro Núcleo Regional do Geopark Bodoquena-Pantanal no município de Nioaque-MS vem transformando a realidade local, trazendo um novo segmento turístico e, consequentemente uma nova forma de renda local. Mas para que isso seja efetivamente aproveitado pela população a proposta é que o município invista em capacitação, fazendo parcerias e criando oportunidades.

\section{Referências}

BOGGIANI, P.C. A aplicação do conceito de geopark da UNESCO no brasil e relação com o SNUC - Sistema Nacional de Unidades de Conservação. Revista Patrimônio Geológico e Cultura, v.1 - n.1, jun. 2010.

BRASIL. Decreto № 12.897, de 22 de dezembro de 2009. Dispõe sobre a criação do Geopark Bodoquena Pantanal, e dá outras providências. Agência Estadual de Imprensa Oficial de Mato Grosso do Sul, Campo Grande, 23 dez. 2009. №7.610, p 7.

DOWLING, R.K. Geotourism's Global Growth. Geoheritage, v.3, n.1, p.1-13, 2011. EDER, F.W.; PATZAK, M. Geoparks - geological attractions: a tool for public Education, recreation and sustainable economic development. Episodes, v.27, n. 1, p. 162-164, 2004.

GHEMAWAT, P. A estratégia e o cenário dos negócios: textos e casos. $2^{\circ}$ Edição. Porto Alegre: Bookman, 2000. 380 p.

IPHAN/MS. GEOPARK BODOQUENA PANTANAL: Dossiê de Candidatura à Rede Global de Geoparks Nacionais: sob Auspício da Organização Das Nações Unidas para Educação, Ciências e Cultura/UNESCO. Out, 2010.

LASCURÁIN, C.H. O ecoturismo como um fenômeno mundial. In: LINDBERG, K.; HAWKINS, E.D. (Orgs.) Ecoturismo: um guia para planejamento e gestão. São Paulo: Senac, 2011.

LICCARDO, A.; NETO, V.M.; PIEKARZ, G. Geoturismo Urbano: Educação e Cultura. Anuário do Instituto de Geociências, v. 35, n. 1, p. 133-141, 2012.

MANOSSO, P. C. Geoturismo: uma proposta teórico-metodológica a partir de um estudo de caso no município de Apucarana-PR. Caderno Virtual de Turismo, v. 7, n. 2, p. 47-56, 2007. 
MC KEEVER, P.J.; ZOUROS, N. Geoparks: Celebrating Earth heritage, sustaining local communities Episodes. Journal of International Geoscience, v. 28 , n. 4, p. 274-278, 2005.

MEDEIROS, C A.F.; GOMES, C.S.C.D.; NASCIMENTO, A.L. Gestão em Geoparks: Desafios e Realidades. Revista Brasileira de Pesquisa em Turismo, v. 9, n. 2, p. 342-359, 2015.

MOREIRA, J.C. Geoturismo e interpretação Ambiental. Ponta Grossa: UEPG, 2011. $157 \mathrm{p}$.

NASCIMENTO, M.A.L.; RUCHKYS, U.A.; NETO, V.M. Geoturismo: um novo segmento de turismo no Brasil. Global Turism, v. 3, n. 2, p. 1-24, 2007.

PERINOTTO, R.C. Geoturismo: uma nova forma de atração turística: estudo de caso na alta bacia do rio Corumbataí, SP. SeTur/SBE, v.2, n.1, p.27-39, 2009.

SCHOBBENHAUS, C.; SILVA, C.R. Geoparks do Brasil: propostas. Rio de Janeiro: CPRM - Serviço Geológico do Brasil, 2012. 745p.

SOARES, A.J.S. et.al. Divulgação das Geociências no Núcleo Regional de Nioaque, Geopark Bodoquena-Pantanal, Mato Grosso do Sul, Brasil. Comunicações Geológicas, 2014, p.101, Especial III, 1383-1386.

URQUÍ, L.C. Instituto Geoconservación. Catarata Geológico y Minero de España, 2012. $126 \mathrm{p}$.

ZOUROS, N. The European Geoparks Network. Geological heritage protection and local development. Episodes, v. 27, n. 3, p. 165-71, 2004.

Alessandra Trotta: Universidade Estadual de Mato Grosso do Sul, Dourados, MS, Brasil.

E-mail: trotta0448@gmail.com

Link para o currículo Lattes: http://lattes.cnpq.br/1306947541212814

Dores Cristina Grechi: Universidade Federal de Mato Grosso do Sul, Dourados, MS, Brasil.

E-mail: cgrechi@uol.com.br

Link para o currículo Lattes: http://lattes.cnpq.br/5735568745884520

Emerson Machado de Carvalho: Universidade Federal da Grande Dourados, Dourados, MS, Brasil.

E-mail: carvalho.em@gmail.com

Link para o currículo Lattes: http://lattes.cnpq.br/7341724276580365

Data de submissão: 23 de março de 2016

Data de recebimento de correções: 12 de junho de 2017

Data do aceite: 12 de junho de 2017

Avaliado anonimamente 